\title{
Health and behaviour
}

\section{A. Mohit}

SUMMARY This paper describes the changing concepts of health and disease including the burden of disease and the effect of biological, psychological and social factors on health. In particular, the impact of behaviour on health is discussed and means of affecting behaviour for health, such as religion, are described.

\section{Concepts of health and disease}

The concepts of health and disease and the patterns and priorities of health needs are changing. Although the populations of many countries of the Eastern Mediterranean Region still face real dilemmas related to infectious diseases and nutrition, these are no longer our only priorities. Comparison of World Health Organization data for different parts of the world, including the countries of this Region, clearly shows the emergence of a new pattern in the prevalence of the diseases that will undoubtedly affect the order of priorities in the long list of health needs. Other studies have demonstrated that the classical mortality-oriented epidemiology is no longer capable of representing the true burden of diseases [ 1$]$.

The true or global burden of disease can be calculated if we add premature mortality to disability and total days lost to illness. One may even argue that the individual's and family's emotional and other suffering and losses should also be calculated and added to this burden. Furthermore, there is a growing number of studies in both basic and clinical sciences that show a clear relationship between the biological, psychological and socioeconomic aspects of human life and health and disease. For instance, it is a well known fact that emotions and thoughts affect the biochemical, immunological, endocrine, neuroendocrine and neurological functions that are in control of the whole working of the body. New insights have been gained into the mechanisms of homeostasis. We now have a deeper understanding of the mechanisms for maintaining an overall stability through the constant adjustment and balancing of various body components and functions in response to stress.

The new concepts of allostasis and allostatic load refer to these new understandings and have paved the way for meaningful theory formation and scientific work in the field of the mind-body relationship [2-4]. In this new concept of disease and health, allostasis refers to the process of adaptation and connotes the maintenance of stability (homeostasis) through change. It is the process of adaptation to a challenge. Allostatic load, on the other hand. is the wear and tear of the body as a result of repeated allostasis responses. This load is more than the mere sum of chronic stress. It also reflects all the genetic and developmental and environmental factors that can affect the efficiency of the person's response [5]. In other words, many reciprocal links exist between the central

\footnotetext{
'Regional Adviser, Mental Health: Team Coordinator, Mental Health and Social Change, Division of Health Protection and Promotion, World Health Organization Regional Office for the Eastern Mediterranean. Cairo. Eoyot.
}

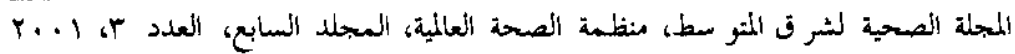


nervous systern, which recognizes the experiences; the endocrine system, which produces hormones that govern many body functions; and the immune system, which organizes responses to infections and other challenges [6]. Many of the pathways of this multilayer system are known and the issue is no longer regarded as pure speculation. In short, when we talk about human health and disease, we need constantly to remind ourselves of a continuous dynamic interaction between different biological, psychological and social levels and layers. Body, information, behaviour and emotions are all parts of this dynamic, interactive, open system.

\section{Behaviour affects health}

A number of studies have shown that psychosocial factors, particularly behaviour, can greatly contribute to enhancing or compromising health. Examples are many and include cigarette smoking, abuse of different substances including alcohol, unhealthy dietary habits, sedentary lifestyles and non-adherence to effective medication regimens. Even successful programmes for immunization have many behavioural determinants and can undoubtedly benefit from proper interventions in this area. Thus it is clear that both access to health care and regard for its advice are hehaviourally influenced [5]. In short, the oversimplistic view of "one disease, one etiology", which dominated medicine and health in the early years of modern medicine, is no longer valid; instead, a holistic view of health and disease is emerging.

Nevertheless, enough evidence exists at the global level to show the effectiveness of mary behavioural interventions in enhancing health, reducing the harm caused by illnesses, increasing the life of patients with terminal illnesses and adding to the quality of life of many people. Research has shown, for example, that women with advanced breast cancer who participate in group therapy live significantly longer than those who have no such experience [7]. Some studies show that there is a direct relationship between non-treated depression and the incidence of coronary heart disease [8]. Since depression is a treatable condition, it is clear that treatment of depression can decrease the incidence of coronary heart disease. Other studies show that realistic acceptance of one's own death has a positive effect on the duration of survival of patients with acquired immunodeficiency syndrome (AIDS) [9]. The interrelatedness of human thoughts, emotions, behaviour and relationships - people's inner world - with a range of illnesses is now receiving more than anecdotal coverage and is the subject of the work of many study groups and articles in leading medical and public health journals [ $10-13]$.

\section{Affecting behaviour for health}

People's attitudes and behaviour are determined by many factors. Individual character traits genetic make-up and family norms are internalized through the laws of biology and childhood learning. Local and national characteristics and customs continue to live in individuals through cultural demands and reinforcements. Even history and mythology become important in influencing people's mind and behaviour. Therefore, any outside message intending to affect behaviour and behavioural patterns must take into account these factors, which are usually more influential than any outside message. People's behaviour and attitudes can vary considerably in areas such as: the environment, substances that 
have abuse potential, reproduction and sexual conduct, dietary habits, use of medication. We need to recognize these factors, study their forms and impacts and consider them whenever we plan a health programme, in order to enhance the effectiveness of the programme.

The role of religion, faith and belief systems in health is very clear. People believe through their hearts and minds. Many of them accept the limitations imposed on them by religion and enjoy, without guilt, the privileges offered by their religious code. Therefore, the use of religion for the promotion of health is a great asset. However, to be able to use faith as a health-promoting tool, we need to study seriously all aspects of the issue with scientific methodolugy. We necd to analyse different means of using religious beliefs more effectively for the advancement of health. We need to know when and where enforcing a rule, a religious decree or fatwa works best, and if there are instances when it does not have an impact, what is the reason? How decply has the issue of the possible misuse of people's religious beliefs been considered and exannined? Furthermore, the role and obligations of the religious schools and scholars should be addressed. There is a need to include health topics in the curriculum of the future generations of religious leaders. We must also find a mechanism for dynamic dialogue between rcligious scholars and national leaders regarding health issues. Although our Regional Office has been active in this regard', such activities necd to be enriched with well defined goals and visions, and their achievements should be evaluated with clearly measurable indicators.
Another important issue is health promotion, health education and promotion of healthy lifestyles. In the past two decades, these programmes have been a major part of the Regional Office's health strategy and have made a number of significant achievements, such as the Action-oriented School Health Curriculum. It is important to enable these programmes to benefit from the major developments in information and audiovisual technology and advances in areas like behavioural sciences and communication. There is a need for a dynamic cooperation with the Public Information Unit of the Regional Office with these programmes. For instance, innovative approaches to involve the media in health promotion require an atmosphere of reciprocal lcarning which can be technically arranged through such a collaboration. Films and videos can be a powerful tool in the promotion of health. The creation of a film is a delicate and complex process that requires deep understanding of the subject, the pcoplc and target groups and the interplay between the human mind and the images. Thus, the behavioural and psychological aspects and impact of each film need to be carefully evaluated to ensure that the intended message is conveyed in the best possible way.

\section{Conclusion}

This paper has tried to summarize the most important facts regarding the emerging trends, issues and challenges for health in relation to human behaviour. The fundamental argument of this paper is that health

'The Regional Office has published its series: The Right path to health; health education through religion and has collaborated with the Islamic Association for Medical Sciences on mental health legislation and prevention of substance abuse.

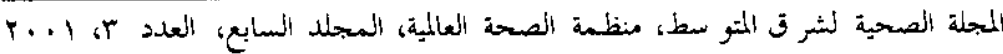


is a highly complex human issue which cannot be understood only in terms of simple biological causality and body functions. Even the scemingly most direct cause-andeffect relationships in the etiology of diseases, such as a bacterium causing an infection, are subject to influence by many factors, including human feelings, thoughts and behaviour. As a rule, the greater the complexity of an issue, the more interdisciplinary it becomes. In planning to address the interdisciplinary issues, we not only deal with parts of an open system, but with the relationship between the parts, which requires further development of holistic methods. Once one understands and is convinced of the effects of behaviour, atti- tudes, social factors and the like on all aspects of health, then the real challenge is to find methods and means to make holistic issues measurable. It is only through measurements that we can set targets and evaluate our interventions. We also need to draw up a strategy for using behavioural interventions that will have the greatest impact on the health of the people of the Region. It only beconnes possible through a system of concerted, multisectoral and integrated efforts directed towards making the best use of the resources of many different disciplines. A dedicated team for behaviour and health would address these issues.

\section{References}

1. Murray Christopher JL et al. The global burden of disease. Geneva, World Health Organization, 1996:324-51.

2. McEwen BS Stellar E. Stress and the individual: mechanisms leading to disease. Archives of internal medicine, 1993, 153:2093-101.

3. McEwen BS. Protective and damaging effects of stress mediators. New England journal of medicine, 1998 , 338:171-9.

4. McEwen BS and Sooman T. Protoctive and damaging mediators of stress: elaborating and testing the concepts of allostasis and allostatic load. Annals of the New York Academy of Sciences, 1999, 896:30-47.

5. Institute of Medicine. Health and behaviour. The interplay of biological, behavioral and societal influences. Report of the Committee on Health and Behavior: Research, Practice and Policy Board on Neuroscience and Behavioral Health.
Washington DC, National Academy Press, 2001.

6. World health report. New understanding, new hope. Geneva, World Health Organization, 2000.

7. Spiegel D et al. Effect of poychosocial treatment on survival of patients with metastatic breast cancer. Lancet, 1989 , 2(8668):888-91.

8. Ferketich AK et al. Depression as an antecedant to heart disease among womon and mon in the NHANES I study. Archives of internal medicine, 2000 . 160(9): 1261-8.

9. Reed GM et al. Realistic acceptance as a predictor of decreased survival time in gay men with AIDS. Health psychology, 1994, 13(4):290-307.

10. Angell M. Disease as a reflection of the psyche. New England journal of mediclne, 1985, 312:1570-2.

11. Barefoot JC et al. Depression and longterm mortality risk in patients with coro-

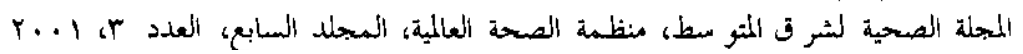


nary artery disease. American journal of cardiology, 1996, 78:613-7.

12. Glaser $R$ et al. The influence of psychological stross on the immune response to vaccines. Annals of the New York Academy of Sciences, 1998, 840:64955.
13. Glaser $R$ et al Stress-induced immunomodulation: implications for infectious diseases? Journal of the American Medical Association, 1999, 281:226870 .

The World Health Report 2001. Mental Health: Mew understanding, New hope

An estimated 450 million people suffer from mental or neurological disorders or from psychosocial problems such as those related to alcohol and drug abuse. Many of them suffer silently. Many suffer alone. Many never receive treatment of any kind. Between the suffering and the prospect of care stand the barriers of st/gma, prejudice, shame and exclusion.

In devoting The Worid Health Report 2001 to mental health, WHO is making one clear, emphatic statement. Mental health - neglected for far too long - is crucial to the overall well-being of Individuals, socletles and countrles and must be universally regarded in a new light. This book is a landmark report that alms to raise professional and publle awareness of the real burden of mental and neurological disorders and the cost in human, social and economic terms. At the same time it alms to dismantle many of those barriers that prevent millions of sufferers from receiving the treatment they need and deserve.

The document can be ordered from: WHO Marketing and Dissemination, CH-1211 Geneva 27, Switzerland. Fax: +227914857 , E-mail: bookorders@who.int. The selling price is: Sw.fr. 15 (5w.fr. 10.50 in developing countries). It is also avallable free on the internet at: http://www. who.int/whr/

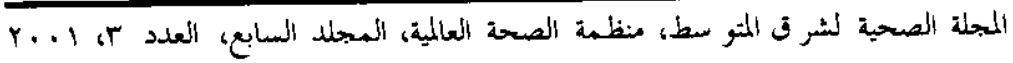

